\title{
APRENDIZAGENS E VIDEOGAMES ${ }^{1}$
}

\author{
APRENDIZAJES Y VIDEOJUEGOS
}

\author{
LEARNING AND VIDEO GAMES
}

\author{
Leticia Staub LIMBERGER ${ }^{2}$ \\ César Augusto MÜLLER ${ }^{3}$ \\ Maira Meira PINTO ${ }^{4}$
}

\begin{abstract}
RESUMO: A presente pesquisa parte do paradigma da complexidade e problematiza os videogames enquanto objetos técnicos, espaços relacionais abertos, dialógicos e imprevisíveis. Sua imprevisibilidade abre caminhos para explorarmos as dimensões do humano no que se refere ao acoplamento estrutural e à autopoiesis, conceitos essenciais para configurar entendimentos acerca da aprendizagem por meio do uso de videogames. A pesquisa que ora se apresenta tem como aporte metodológico o método cartográfico, que pertence ao presente, e se refere a um processo que está acontecendo, uma ação que está sendo desenvolvida para conhecer uma realidade. A realidade que buscamos configurar/conhecer é a de um grupo de adolescentes de Santa Cruz do Sul e sua relação com os videogames. O texto será narrativo, como forma de dar corporeidade à experiência/vivência que se se produz junto ao grupo.
\end{abstract}

PALAVRAS-CHAVE: Videogames. Aprendizagem. Paradigma da complexidade. Cartografia.

RESUMEN: La presente investigación parte del paradigma de la complejidad y problematiza los videojuegos como objetos técnicos, espacios relacionales abiertos, dialógicos e imprevisibles. Su imprevisibilidad abre caminos para que se explore las dimensiones del ser humano en lo que se refiere al acoplamiento estructural y a la autopoiesis, conceptos esenciales para configurar entendimientos acerca del aprendizaje por medio del uso de videojuegos. La investigación que presentamos posee como aporte metodológico el método cartográfico, el cual pertenece al presente y se refiere a un proceso que está ocurriendo, una acción que está siendo desarrollada para conocer una realidad. La realidad que intentamos configurar/conocer es la de un grupo de adolescentes de Santa Cruz do Sul y su relación con los videojuegos. El texto será narrativo, como forma de dar corporeidad a la experiencia/vivencia que se produce junto al grupo.

PALABRAS CLAVE: Videojuego. Aprendizaje. Paradigma de la complejidad. Cartografía.

ABSTRACT: This research uses the complexity paradigm to discuss videogames as technical objects; open relational spaces, dialogic and unpredictable. Its

${ }^{1}$ Fundação de Amparo à Pesquisa do Estado do Rio Grande do Sul.

${ }^{2}$ Universidade de Santa Cruz do Sul. Email: lestaub@gmail.com

${ }^{3}$ Universidade de Santa Cruz do Sul. Email: cesar@unisc.br

${ }^{4}$ Universidade de Santa Cruz do Sul. Email: mmeirapinto@gmail.com

RIAEE - Revista Ibero-Americana de Estudos em Educação, v. 11, n. 3, p.1149-1168, 2016. 
unpredictability allows us to explore the human dimensions regarding the structural coupling and the Autopoiesis, essential concepts to understand learning through videogames. The research presented here has as methodological approach the cartographic method, which belongs to the present, and refers to a process that is happening, an action that is being developed to meet a reality. The reality we seek to set I know is that of a group of teenagers from Santa Cruz do Sul and its relation to videogames. The text is narrative as a way to give embodiment to the experience which is produced by the group.

KEYWORDS: Videogames. Learning. Paradigm of complexity. Cartography.

\section{Introdução}

A presente pesquisa parte do paradigma da complexidade, que se opõe, como todos os paradigmas, segundo Kuhn (1970), àquele que o precedeu, o mecanicista. Salientamos que o mesmo, conforme Müller e Oliveira (no prelo), prevalece em muitas pesquisas de várias áreas do conhecimento, entre elas as de educação formal e não formal. Nesse sentido, a presente investigação estabelece relações à dimensão educacional não formal e informal.

O balizador do Pensamento Complexo (MORIN, 2008), é a noção de união, ou seja, tudo está interligado. Isto posto, devemos, segundo Morin (1993), começar a entender que o nosso universo, nosso mundo, é concebido por meio de relações complexas de ordem/desordem/organização. Movimentos que unem, mas que não fornecem a chave do que é real e, sim, viabilizam que se compreenda melhor o que está em jogo - o jogo da biodegradação (MORIN, 1996).

Certamente, oposto radical para com a ciência clássica que se alicerça ainda nas bases da ordem, da separabilidade e da lógica que, segundo o autor, de Descartes a Newton, passando por Laplace, o determinismo se instaurou há quase 400 anos por meio do paradigma tradicional da ciência, introduzindo a racionalidade centrada na previsão da matematização da experiência. Ou seja, para a ordem, o determinismo; Frente a um problema de difícil resolução, separe o todo em partes, pois conhecer é separar (separe também o observador do objeto observado/elimine a subjetividade e o próprio observador), pois quanto mais cindido e neutro, melhor será a lógica da indução (observações), para se chegar à verdade absoluta do fenômeno observado.

Por outro lado, para o pensamento complexo, os conhecimentos científicos não são o reflexo do real, mas projeções do homem sobre esse real. São, nas palavras de Atlan (1993), os interpretandos da realidade em questão, e somente aí, conforme Morin 
(1993, p. 84), o nosso "olhar sobre o olhar que olha" se fará a possibilidade de explicar e compreender a "realidade viva sem mutilá-la demais".

Há uma grande diferença entre dizer que existe uma realidade e pretender conhecê-la. Não negamos que exista uma realidade; negamos simplesmente o fato de que uma teoria ou tradição que permita uma concepção exclusiva da realidade rotule esta com o qualificativo de "última", como se não se pudesse ir além dela. Pensamos poder sempre haver um maior aprofundamento, e por isso não há "realidade última". A realidade pode ser interpretada, ela é feita daquilo que chamamos de "interpretandos" (ATLAN, 1993, p. 67).

Entretanto, em alguns sistemas educacionais formais, ainda há ensinamento/treinamento (MATURANA, 2011) para se pensar separadamente, por meio de disciplinas e conteúdos isolados. Ocorre que estas separações nos levam a buscar e acreditar na simplicidade ao reduzirmos as dificuldades, bem como suas resoluções. Uma vez alavancadas, de acordo com Gubes (2015), nos conduzem para elaboração de ideias/conceitos precipitadamente, limitando o conhecer, o aprender e o viver, por estarmos limitados pela repetição automática de um modelo dado.

$\mathrm{Na}$ educação e na cultura contemporâneas, ainda persiste com muita força a herança da modernidade, pois é uma visão dilacerada que fragmenta as diferentes dimensões do existir e não contempla necessidades básicas do ser humano de forma integrada e integradora, tais como o amor. Ou seja, "a marca humana de rede [...], a autoria ou a dimensão autopoiética, a necessidade abdutiva de fazer relações sobre os fenômenos da realidade e tantas outras" (PELLANDA; BOETTCHER, 2012, p.12).

Toda nossa sabedoria consiste em preconceitos servis; todos os nossos usos não são senão sujeição, embaraço e constrangimento. $\mathrm{O}$ homem civil nasce, vive e morre na escravidão; ao nascer, envolvem-no em cueiro; ao morrer, encerram-no em um caixão; enquanto conserva sua figura humana está acorrentado às nossas instituições (FALABRETTI, 2012, p. 182).

Para Pellanda (2008), privações que originam sofrimento pelo impedimento da criação de sentido à vida. Pois a educação que possuímos e, por extensão, o contexto cultural, em muitos momentos, nos incapacita a lidar com nós-outros e com o sofrimento.

A educação enquanto fenômeno cultural atende/serve aos interesses da cultura e da sociedade, mas não ao homem. Falamos, para evidenciar que a prática acima descrita 
traz um elemento significativo para o entendimento atual, de uma educação voltada à dependência no sentido de exclusão de uma educação que potencialize e complexifique o aprender e viver.

\section{Complexidade: videogames e aprendizagem}

É comumente aceito conforme Müller e Oliveira (no prelo), que a cibernética bem como a termodinâmica e a biologia, possuiu um papel muito importante no estabelecimento do paradigma da complexidade. A Cibernética teve como princípio base estudar os mecanismos de autoregulação maquínicos.

A palavra cibernética foi forjada por volta de 1943, conforme Oliveira (2009), por Norbert Wierner e Arthur Rosembleuth, para dar unidade ao movimento ciberneticista visando estudar o funcionamento de regulação e autoregulação em máquinas e nos seres vivos, bem como a comunicação e construção de aparelhos que pudessem criar e implementar informação/comunicação. Outra configuração importante foi a de compreender como armas programadas funcionam, ou seja, por meio de instruções (informações) para procedimentos automáticos (de)codificados - como, por exemplo, detonação à distância e/ou armas autoprogramadas.

Se em um primeiro momento, conforme Müller e Oliveira (no prelo), o objetivo dos ciberneticistas foi tentar construir máquinas que possuíssem a complexidade de funcionamento de um ser vivo - sem êxito; Em um segundo momento, buscaram compreender o cérebro humano como se tratasse de uma máquina - Inteligência Artificial (IA). Ou seja, conhecer é simular.

Nesse sentido, conhecer será produzir um fenômeno e efetuar sobre ele manipulações ordenadas. Daí podemos compreender que "todo conhecimento é reprodução, representação, repetição, simulação" e isso "caracteriza o modo científico, racional de conhecimento" (DUPUY, 1996, p. 27). Por meio da modelização, o conhecer é produzir um modelo do fenômeno e efetuar sobre ele manipulações ordenadas como reproduzir, representar, repetir, entre outros, por exemplo, que caracterizam o modo científico e racional do conhecimento.

Assim, as faculdades da mente serão sempre, e apenas, as propriedades de sistemas de processamento de informação, pois conhecer é efetuar e simular sobre representações, ordenadas e regradas - paradigma dominante nas ciências cognitivas. 
[...] human understanding is not primarily a matter of storing general concepts in the head or applying abstract rules to experience. Rather, humans think and understand best when they can imagine (simulate) an experience in such a way that the simulation prepares them for actions they need and want to take in order to accomplish their goals (GEE, 2005, p.03)

Por outro lado, a influência da Cibernética para o paradigma da complexidade reside, sobretudo, segundo Müller e Oliveira (no prelo), nas contribuições dos autores da $1^{\text {a }}$ corrente, entre eles von Foerster, Norbert Wiener, entre outros (OLIVEIRA, 1999). Todavia, a mais importante diz respeito ao observador como elemento construtor da pesquisa. Entretanto, existem outras características importantes no paradigma da complexidade, entre elas a recusa em resumir e/ou olvidar os dados verificados Morin (2008).

Dito de outra maneira: em vez de se desprezar aquilo que coloca em causa as hipóteses de pesquisa ou as questões de partida, se aceita esses elementos contraditórios como potencializadores de mais aprendizagens, por serem transformados de ruídos em ordem de um nível diferenciado do anterior no qual nos encontrávamos («order from noise» [7]; «princípio de complexificação pelo ruído» [8]). Ruídos e perturbações no modo como usualmente atribuímos sentido ao mundo e que usualmente produzem aprendizagens mais ricas do que aquelas vinculadas em torno de instruções muito organizadas, em forma de informação, como ainda ocorre em algumas situações na educação formal. (MÜLLER; OLIVEIRA, no prelo)

Foi com essa base conceitual que se forjou nossa investigação, pela qual gradualmente pesquisador e pesquisados formaram uma unidade complexa (MORIN, 2008). Porém, várias são as teorias que constituem o paradigma da complexidade.

Para a presente pesquisa utilizamos a teoria da biologia da Cognição, de Maturana e Varela (1997); Varela (1994), que conta dois conceitos importantíssimos, o de autopoiesis, que nos faz compreender a "singularidade de cada ser vivo pela sua organização fechada (mas não isolada) que ocorre simultaneamente na interação estrutural com outros seres vivos. " (MÜLLER; OLIVEIRA, no prelo), e o de Acoplamento estrutural.

Em sua teoria, Maturana e Varela (1997); Varela (1994) apontam para o funcionamento dos seres vivos enquanto autoprodutores de si mesmos. Sua autoprodução é proporcionada pela complexificação pelo ruído (ATLAN, 1992), permitindo que os seres vivos se (re) configurem continuamente, sempre dentro de um 
sistema fechado. Os conceitos de Autopoiesis e acoplamento estrutural são essenciais para entender a teoria da biologia da Cognição, assim como proporcionam uma nova visão acerca da aprendizagem por meio da utilização de videogames.

O conceito de Autopoiesis originou-se de dois vocábulos gregos: auto, que significa - por si - e poiesis, que tem como significado - criação. Nesse sentido, entende-se os seres vivos enquanto produtores de si mesmos, capazes de organizarem-se enquanto sistema vivo por meio da autonomia, garantindo assim sua sobrevivência. Assim temos o entendimento que os seres vivos são capazes da autoprodução de células no seu processo vivo de operar. Segundo Maturana e Varela (2001, p.57) “donde se conclui que não há separação entre produtor e produto". Para Pellanda (2009, p.24), “os seres vivos são máquinas autopoiéticas porque o resultado de seu operar é sempre eles mesmos". O conceito de Autopoiesis, como vimos, permite que o humano se configure e reconfigure a todo momento frente às perturbações e ruídos exteriores. O que nos leva ao segundo conceito, de acoplamento estrutural, no qual Maturana e Varela (1997) buscam entender a maneira como o sujeito estabelece interações com o meio, a forma como se relaciona com os ruídos do mundo exterior.

Essa complementariedade estrutural necessária entre o sistema determinado por sua estrutura e o meio - que eu qualifico de acoplamento estrutural - é uma condição de existência para todo o sistema. A parte do meio no qual é um sistema distinguido, isto é, a parte do meio que é operacionalmente complementar a ele. (MATURANA; VARELA, 1997, p. 87).

O acoplamento estrutural é um conceito muito importante, pois ele não estabelece rigidez, mas sim uma produção a partir das relações, não se restringindo a uma parte da realidade, mas ao seu todo. Poderia de forma simples ser definido como a: "relação entre o sistema vivo e seu meio na qual as interações do sistema são apenas perturbações. Elas se dão de tal maneira que daí emerge o trabalho de constituição dos seres vivos." (PELLANDA, 2009, p. 107). Oliveira (1999, p. 51) aprofunda o pensar sobre esse conceito quando reflete que as

[...] mudanças estruturais de um ser vivo decorrem das mudanças estruturais do meio a que o organismo se adaptou; esse meio constitui o nicho desse organismo, já que decorre das interações de componentes que se tocam e se especificam via processos de acoplamento, entre o meio (aos olhos de um observador) e um organismo.

Por consequência, evidenciamos a importância do conceito de acoplamento 
estrutural para pensarmos a complexidade e também a sua relação com o conceito de autopoiesis, visto que as perturbações desencadeadas pelos acoplamentos estruturais compreendem também a manutenção da autopoiesis, potencializando a complexificação do humano por ele próprio.

\section{Do objeto técnico: videogames}

Imaginar a vida dos seres humanos contemporâneos sem tecnologia é uma tarefa árdua, pois estamos cercados de instrumentos tecnológicos que transformam nossa maneira de aprender e viver. O ser humano é tecnológico (ORTEGA Y GASSET, 1991), inventor de técnicas e instrumentos para dar conta de situações específicas, incorporando as mesmas na maneira como aprende e vive.

Assim, os videogames são mais uma tecnologia, um recurso, fabricado pelo homem, que poderá potencializar e ser gerador de ruídos, instaurando a criação de conhecimento outro, alterando os entendimentos da técnica, vida e da própria invenção de si. Afinal, a vida, de acordo com Ortega y Gasset (1991), é um que-fazer constante. E nessa dinâmica o homem tem de fazer-se a si mesmo, se autofabricar, pois o homem se encontra na situação do técnico. Isto porque o homem, para viver, tem que se esforçar para que exista o que ainda não existe. Ou seja, ele próprio.

Segundo Lévy (1996, p.15) "a palavra virtual vem do latim medieval virtualis, derivado por sua vez de virtus, força, potência". O virtual, nesse sentido, se coloca em contraposição ao atual, no sentido de existir apenas em potência, mas não no atual, como, por exemplo, uma árvore existe em potência dentro da semente, mas não na atualidade, apenas na realidade de potência. O conceito de potência também é encontrado em Nietzsche (1992). Este autor aponta a perseverança apresentada pelo ser humano em prosseguir, buscando diferentes caminhos até então não percorridos. Nesse sentido, a potência é um conceito presente no dia a dia da humanidade, traduzida pela força em realizar mudanças cotidianas, num constante vir a ser de novas interações, possibilitadoras de novas reconfigurações.

A técnica faz parte da vida humana. Compreende-se então que a construção de uma dada ferramenta para um certo uso, por mais específico que seja, acaba geralmente por revelar outras possibilidades além da prevista. Assim, dependendo de como for usada a técnica, poderá potencializar aprendizagens implicando a própria criação e entendimento do ser/conhecer/viver a própria realidade. Nesse sentido, Lévy (1999, p. 
26) destaca:

[...] uma técnica não é nem boa, nem má (isto depende dos contextos, dos usos e dos pontos de vista), tampouco neutra (já que é condicionante ou restritiva, já que de um lado abre e de outro fecha o espectro de possibilidades). Não se trata de seus "impactos", mas de situar as irreversibilidades às quais um dos usos nos levaria, de formular os projetos que explorariam as virtualidades que ela transporta e de decidir o que fazer dela. (Grifo nosso)

Lévy (1993) sustenta que a informática (acrescentamos o videogame) - como técnica, ferramenta, são lunetas que podem, ou não, viabilizar o conhecer, aprender para viver diferido, gerando outros modos de reflexão, informação, transformando radicalmente nosso viver no mundo, nos forçando para ações criativas. Ancoramos essa afirmação primeiramente quando da origem de uma dada ferramenta em virtude da necessidade física e/ou mental do homem é verificada - o que-fazer constante de Ortega y Gasset (1991). Após esse movimento, separa-se a experiência interior e subjetiva, originando um dispositivo híbrido. O que antes foi necessidade subjetiva agora torna-se um objeto, uma ferramenta - objeto técnico.

Entretanto, salienta o autor que para a exterioridade técnica gerar efeitos é necessário ser internalizada novamente, gerando efeitos diferidos em uma espiral sobre espirais em circularidade. Isto porque, para "[...] utilizar uma ferramenta, deve-se aprender gestos, [...] recompor uma identidade mental e física". Em simultaneidade, "a dinâmica técnica se alimenta de seus próprios produtos, opera combinações transversais, e conduz finalmente [...] a arranjos complexos muito afastados de funções corporais simples" (LÉVY, 1996, p. 74).

As reflexões do autor salientam a virtualização de funções motoras, cognitivas e/ou termostáticas que não podem ser confundidas como sendo prolongamentos de corpos individuais. Serão de modo pleno interiorizadas novamente em uma graduação de "megamáquinas sociais hibridas ou de hipercorpos coletivos. " (LÉVY, 1996, p. 74)

A concepção de uma outra ferramenta virtualiza uma combinação de órgãos e de gestos que só aparece, então, como uma solução especial, local, momentânea. Ao conceber uma ferramenta, mais do que nos concentramos sobre determinada ação em curso, içamo-nos à escala bem mais elevada de um conjunto indeterminado de situações.

O surgimento da ferramenta não responde a um estímulo particular, mas 
materializa uma função genérica, cria um ponto de apoio para a resolução de uma classe de problemas. "A ferramenta que seguramos na mão é uma coisa real, mas essa coisa dá acesso a um conjunto indefinido de usos possíveis" (LÉVY, 1996, p. 75).

Para o autor, as ferramentas são mais que uma extensão do corpo. São virtualizações de ações. Resumidamente, a mesma ferramenta - objeto técnico - pode ser considerada a partir de quatro modos de existir: problematizador, desterritorializador, passagem ao público, metamorfose e recomposição de funções corporais. O objeto técnico torna-se, assim, um operador de virtualizações.

Por fim, com esses tons em nossa trama, não pretendemos, conforme Simondon (2007), criar entendimentos dos videogames como sendo técnicas estrangeiras que aprisionam o humano, escravizando-o, bem como a própria técnica, gerando o não conhecimento de valores implicados nas relações humano/não humano/humano. Isto porque a técnica é rica em esforços humanos e em estruturas que funcionam e poderão ser utilizadas com a maior abertura e liberdade para uma complexificação do sujeito para conhecer e viver, pois também somos máquinas. Entretanto, conforme Atlan (1992), não rígidas como o cristal nem tampouco evanescentes como a fumaça: somos máquinas desejantes e imprevisíveis.

\section{Acontecimentos: tratamento dos registros}

A pesquisa que nos propomos a discutir por meio desse artigo está ancorada teoricamente no paradigma da complexidade, conforme apresentado, utilizando-se de metodologia cartográfica para dar conta do tratamento dos registros. A cartografia como ciência volta seus estudos para a construção e compreensão de mapas, com a finalidade de orientar as pessoas no que se refere a sua localização. Essa localização não pertence apenas ao plano do aqui e agora, onde o observador procura localizar-se exatamente onde se encontra, ela também amplia sua lente para a visualização de um caminho percorrido, ou mesmo para a possibilidade de planejar por onde se deseja locomover, traçando um novo percurso.

Para o delineamento da metodologia dessa pesquisa, contamos, portanto, com o método cartográfico, porém no que ele se refere ao estudo topológico. Ao contrário dos estudos topográficos, que buscam delinear o relevo de uma região para a confecção de mapas fixos e permanentes, os estudos topológicos levam em consideração as 
constantes transformações do relevo, produzidas pela interação do homem com a natureza, abrangendo assim seus aspectos mutatórios.

Entender o ato de pesquisar em relação ao aspecto topológico permite potencializar questões referentes à criação e à transformação do espaço pesquisado, viabilizando interferências e correções de "curso" nos laboratórios se necessário (BOETTCHER, 2003).

Ao pesquisar à luz dos pressupostos da complexidade, nos deparamos com elementos de cunho topológico, visto que não existem caminhos prontos; os mesmos devem ser construídos no decorrer da pesquisa, a cada passada. $\mathrm{O}$ ato de cartografar pertence ao presente, se refere a um processo que está acontecendo, uma ação que está sendo desenvolvida para conhecer uma realidade, portanto:

Sendo tarefa do cartógrafo dar língua para afetos que pedem passagem, dele se espera basicamente que esteja mergulhado nas intensidades de seu tempo e que, atento às linguagens que encontra, devore as que lhe parecem elementos possíveis para a composição das cartografias que se fazem necessárias (ROLNIK, 2006, p. 23).

A realidade que buscamos configurar/conhecer é a de um grupo de adolescentes de Santa Cruz do Sul e sua relação com os videogames. O texto será narrativo, como forma de dar corporeidade à experiência/vivência que se se produz junto ao grupo. A experiência que ora se relata acontece todas as segundas-feiras à tarde com um grupo de adolescentes na Universidade de Santa Cruz do Sul - UNISC. Estes adolescentes são oriundos de um bairro da periferia de Santa Cruz do Sul e participam das atividades do "Games" a partir de uma parceria com o Grupo de Pesquisa GAIA (Grupo de Ações e Investigações Autopoiéticas) e com o Projeto de Extensão Semear Amigos, ambos desenvolvidos na Universidade de Santa Cruz do Sul.

Os primeiros encontros serviram para que os participantes e a pesquisadora, em parceria com bolsistas e demais pesquisadores, pudessem estabelecer um vínculo. Neste sentido, foi explicada aos jovens a proposta dos encontros, sua dinâmica, e a importância de eles estarem ali de maneira à realmente participar/viver das atividades propostas, fundamentadas no 'jogar videogame'.

Com o passar dos encontros, observamos que nas processualidades cartografadas, a dinâmica dos mesmos tornou-se mais fluida, uma vez que sujeitos, bolsistas e pesquisadores tiveram a oportunidade de estabelecer uma relação de confiança, permeada por interesses em comum. Os encontros passaram a ser 
produzidos, portanto, pela proposição de algum jogo, oferecido/disponibilizado pela pesquisadora. A partir disto, os adolescentes têm a opção de jogar o que é disponibilizado e de navegar nas redes sociais. De modo geral, e de acordo com o que será narrado a seguir, as duas coisas acontecem: num primeiro momento, eles se 'atualizam' nas redes sociais, trocando mensagens e fazendo a leitura do que está 'postado', e num segundo momento eles começam a jogar. Observamos que os adolescentes, quando se propõem a experienciar algum jogo, realmente o fazem, de modo a entregarem-se a intensidade do momento, dedicando sua atenção e determinação à superação dos obstáculos propostos pelos jogos.

De modo a clarificar a experiência que se tem vivenciado junto aos adolescentes no "Games", narraremos os acontecimentos, articulando a esta narrativa uma reflexão dos elementos teóricos que mais vem nos chamando a atenção.

O primeiro encontro tratou de explanar aos participantes quais os objetivos do projeto, assim como buscar conhecer um pouco de cada membro do grupo e seus caminhos percorridos pelo mundo dos games. Todos fizemos uma breve introdução, dizendo nosso nome e nossa idade. Fizemos um rápido questionamento a respeito da trajetória de todos no mundo virtual, se possuíam Facebook, e-mail, blog, se já jogavam, e que tipos de jogos gostavam de jogar.

O elemento a ser destacado deste encontro foi que, ao entrarem na sala (que está dividida em quatro fileiras e duas colunas), eles automaticamente se dividiram entre meninos e meninas. Os meninos sentaram na direita e as meninas na esquerda. Logo pensamos na divisão que também ocorre no mundo dos jogos, quando se rotula jogos para meninas e jogos para meninos, principalmente em sites de jogos online. Foi satisfatório ouvir de uma das meninas, quando perguntávamos a todos quais os jogos que gostavam de jogar (os meninos falavam bem mais, as meninas estavam tímidas), como se fosse óbvio, que ela jogava os mesmos jogos que os meninos.

Ou seja, vivemos em uma era que o uso de rótulos e estigmas a partir daquilo que se experimenta/vivencia ainda está muito presente. $\mathrm{O}$ pensar de maneira complexa também pressupõe que nos 'desamarremos' de estereótipos e (pré) conceitos, pois a constituição de si se dá pela experiência, e não por pressupostos anteriores ao próprio sujeito. Jogar videogames ainda carrega um estigma perante a sociedade. Apesar da indústria dos jogos ter superado a cinematográfica, os mesmos ainda são vistos como uma atividade não digna de investimento de tempo e dinheiro, considerados muitas vezes infantis e descreditados enquanto forma de aprendizagem. 
O estigma surge quando se descortina a incongruência entre o que se espera do indivíduo e o que ele realmente é (a sua identidade real). A estigmatização possui uma natureza de desqualificação social do estigmatizado por parte dos ditos "normais", na medida em que a identidade real do indivíduo aponta atributos físicos, morais ou grupais que são negativos àquela expectativa que antes se tinha sobre sua identidade social virtual (GOFFMAN, 1982).

Alguns jogos citados pelos adolescentes foram os seguintes: - Bomber man; GTA; - Tank; - Culinaria; - Call of duty: black ops; - Need for speed; - Dragon city; Skate mania; - Shadow of the colossus; - Dead trigger 2. Estes jogos apresentam diferentes tipos de desafios, alguns são de estratégia, outros de ação, aventura, simulação, entre outros. Indiferente é o gênero do jogo, o que nos interessa são as aprendizagens que cada um deles proporciona. E essas aprendizagens não são algo quantificável, pois diz respeito a cada jogador. Situações que se mostraram ruídos para um jogador, para outros podem passar despercebidas. E são essas situações ruído que fazem dos jogos uma ferramenta tão rica para aprender, eles são versáteis, cheios de desafios, e estão disponíveis para todos os gostos.

No segundo encontro com o grupo, proporcionamos um momento livre frente aos computadores com acesso à internet no laboratório de informática da UNISC. A intenção desse encontro foi, ao observarmos os caminhos percorridos pelos adolescentes, buscar questionar suas escolhas, interesses e preferências, para poder de fato configurar as cartografias ali presentes.

Com isto, foi possível perceber que nem todos jogaram de fato, alguns apenas entraram no Facebook e olharam vídeos no Youtube. Como a proposta é que joguem, ficamos pensando maneiras para que eles se sentissem com vontade de jogar, pois essa oficina/projeto é um momento onde vamos jogar, e isso é o importante nestes momentos. Em nenhum momento obrigamos ninguém a jogar, apenas indicamos caminhos a serem seguidos, mas os mesmos podem ser recusados, e novos caminhos produzidos. Dentro da teoria da complexidade, o todo é visto como um processo de retroalimentação, no qual o fluxo do viver é dinâmico e caracterizado por perturbações que perturbam e são perturbadas, num círculo ascendente de interações. No desenvolver dessa pesquisa, que se ancora no método cartográfico, no qual o pesquisador também é ator na realidade pesquisada e está implicado no observar, nosso papel é exatamente esse, observar onde o fluxo nos leva, nos adaptarmos as realidades que nos são expostas, e buscar produzir mapas que evidenciem essas experiências que vivenciamos 
junto aos sujeitos da pesquisa.

[...] o operar do observador na linguagem consiste em um modo de viver na recursividade de coordenações de conduta que surgem na comunidade do viver, e que configuram um mundo de objetos perceptivos [...]. A linguagem e o operar do observador, portanto, não requerem nem dão origem a referências a uma realidade externa. $\mathrm{O}$ mundo das descrições e explicações do observador é um mundo de modos de convivência gerador de objetos perceptivos, no qual o observador surge como um deles ao surgir a linguagem (MATURANA, 1997, p.73).

No terceiro encontro, indicamos o demo do jogo Max and the Magic Marker. A escolha deste jogo se deu porque ele proporciona o enfrentamento de situações ruidosas, disparadoras de escolhas e invenções. Apesar das resistências iniciais de alguns, e das constantes reclamações de como o jogo era difícil, eles não pararam de jogar até chegar ao final do demo. Foi a primeira vez que vimos todos jogando ao mesmo tempo, e podese observar que os adolescentes que já tem mais experiência no mundo dos jogos possuem maior autonomia, não perguntam como faz para passar de fase, encontram eles próprios seus caminhos, enquanto aqueles que não tem como hábito jogar videogame pedem auxílio com maior frequência. Ou seja, o viver os jogos permite uma liberdade em relação a esta ação, permite encontrar a sua forma de ser e pensar, de resolver situações desafiadoras, de tornar-se aquilo que deseja ser, alcançando autonomia no decurso da autopoiesis, permitindo a potencialização e complexificação do humano por ele próprio, aprendendo no viver e viver no aprender.

No quarto encontro, sugerimos o uso do site (http://www.clickjogos.com.br). A intenção foi a de deixar emergir nos jovens o desejo por determinados jogos. Assim como nossas escolhas por livros e filmes dizem do lugar ao qual pertencemos no mundo, a escolha por um jogo também explicita esse lugar de pertencimento. Alguns jogaram os mesmos jogos de sempre, como Dead trigger 2, outros exploraram novas possibilidades e jogaram diversos jogos diferentes, em sua maioria de carro e moto. Ficamos satisfeitos quando duas meninas pediram para que as ajudássemos a acessar novamente o jogo Max and the Magic Marker, demonstrando interesse em transitar pelos mesmos caminhos, porém encontrando novos desafios, uma vez que o jogo permite diferentes formas para a resolução dos obstáculos. Neste encontro também criamos um grupo no Facebook chamado "Games - UNISC", para nos comunicarmos durante a semana e para postagem de links de jogos, reportagens, etc. 
No encontro seguinte, a proposta era indicar um determinado jogo, porém, por questões institucionais, não foi possível realizar o que havíamos programado. Entretanto, ao nos posicionarmos frente ao ato de pesquisar pelo viés topológico, foi possível potencializarmos questões referentes à criação e transformação do espaço pesquisado, viabilizando interferências e correções de "curso" nos laboratórios, quando necessário (BOETTCHER, 2003). Dessa maneira, fizemos uma enquete no grupo que criamos no Facebook do projeto, com as seguintes questões: "Qual o jogo que vocês mais gostam e por quê? " e "Vocês acham importante jogar videogame? Por quê?". Todos participaram, respondendo as questões e jogando jogos de seu interesse ao longo do encontro.

No sexto encontro, levando em consideração a relação sujeito/máquina para pensar sobre o conhecer e aprender a partir das experiências vivenciadas com os jovens, resolvemos caminhar com eles e por sugestão deles em direção ao Xbox 360 com sensor de movimento Kinect. Muitos deles, por entre as conversas informais sobre os jogos, demonstraram interesse pelos jogos de movimento disponíveis nesta plataforma. Portanto, neste encontro, saímos do laboratório de informática e nos deparamos com o Xbox 360 e seus jogos de movimento: Kinect Adventures, Dance Central 2 e Kinect Sports. Primeiramente apenas os meninos estavam interessados, evidenciando, é claro, seu interesse em expressarem sua masculinidade, uma vez que apenas jogaram os jogos de boxe. Com o passar do tempo os espíritos foram se alterando e os interesses variando, jogaram ping-pong, vôlei, dançaram, desviaram de obstáculos, mas claro, sempre com muito encorajamento. Algo que nos chamou muita atenção foi a facilidade com que eles entenderam como funciona a forma de controlar o jogo, de escolher as opções, músicas, etc. Apesar de nunca terem jogado esse tipo de jogo pareceu algo natural, que precisou apenas uma demonstração e eles já sabiam como fazer. O encontro seguinte também foi com o Xbox.

Para Gee (2004), os videogames possuem um tipo de linguagem típica, ele postula que a linguagem inerente aos videogames pode ser tão específica e complexa quanto a linguagem acadêmica. Ao jogarmos videogame, uma alfabetização multimídia ocorre - alfabetização entendida como a capacidade de participar de um conjunto de práticas sociais que conciliam modos de fazer, pensar e avaliar algo - pois nos tornamos capazes de reconhecer (equivalente à leitura) e produzir (equivalente à escrita) significados. Além de associar símbolos, sons, gestos e gráficos em busca da comunicação de significados diversos. 
Na leitura de uma história nos deparamos com a tarefa de "representar o que não está representado no texto e de lidar com essas ausências" (OLSON, 1997, p. 110). A leitura que aqui nos referimos não está restrita às páginas de um livro. De acordo com Petry (2014), serão as ausências no texto que determinarão a profundidade da tarefa do leitor. Ao pensarmos que: "toda leitura, em alguma medida, é preenchida, pelo leitor, por palavras que o autor não disse, por ideias que ele exatamente não propôs, por tonalidades que ele não deu" (PETRY, 2014, p. 147). Os jogos enquanto leitura de histórias e narrativas a serem percorridas por personagens que ganham vida no decurso das nossas ações pode ser entendido como uma leitura a ser preenchida pelo leitor/jogador. Cabe a ele decidir o caminho que vai seguir, tornando-se autor de sua própria história.

Os jogos propiciam espaços para a emergência de diferentes formas de vivenciar a narrativa. Apesar de os jogos serem pré-moldados, os percursos construídos, assim como as construções simbólicas frente ao contexto do jogo, são individuais. Murray (2003) entende que a autoria no contexto dos videogames é procedimental, ou seja, está relacionada ao posicionamento criador, de escrever as circunstâncias sob as quais as ações do jogo refletirão nos acontecimentos vivenciados pelo jogador. Portanto, pensamos que essas ações agem como perturbadoras e disparadoras de processos autoorganizativos.

O Oitavo e o nono encontros aconteceram no laboratório de informática. Buscamos, por meio do jogo Snail Bob 8: Island Story do site (http://www.clickjogos.com.br), instigá-los a superar obstáculos. Ao jogar, nossa cognição/subjetivação está em constante devir, num planejar e replanejar frente às novas situações que se apresentam. Além disto, somos seres que vivem em rede, e precisamos do outro sempre. O jogo nos traz mais perto do outro, por mais que seja um jogo individual, se ele for realmente engajador fará com que busquemos meios de nos conectar, seja para superar desafios, seja para elaborar conquistas, seja pelo simples prazer de discutir um assunto comum com outra pessoa que está jogando o mesmo jogo.

Pensamos que a questão do prazer e da alegria são centrais para aprendizagem, nossa potência para aprender está em seu auge quando estamos alegres. Nossa potência de agir aumenta quando experienciamos o sentimento de alegria, e por ele somos afetados, o que causa um bom encontro - seja ele um encontro com o outro, com o jogo ou consigo mesmo - satisfazendo o desejo da própria afirmação da potência (ESPINOSA, 2007). 
Ao estudar um tipo específico de emoção denominado flow - the satisfying, exhilarating feeling of creative accomplishment and heightened functioning -, Csíkszentmihályi (1975) observou que este tipo de sentimento não era encontrado com facilidade no dia a dia das pessoas, entretanto, em atividades relacionadas a jogos era encontrada com abundância. O mesmo questionou-se a respeito da necessidade de encontrarmos em nossa vida mais momentos prazerosos, apontando que:

But if games are the most consistent and efficient source of joyous engagement in our lives, he wondered, then why did real life so infrequently resemble a game? Csíkszentmihályi argued that the failure of schools, offices, factories, and other everyday environments to provide flow was a serious moral issue, one of the most urgent problems facing humanity. Why should we needlessly spend the majority of our lives in boredom and anxiety, when games point to a clear and better alternative? If we continue to ignore what makes us happy, he wrote, we shall actively help perpetuate the dehumanizing forces which are gaining momentum day by day (MCGONIGAL, 2011, p. 93).

Aparentemente estamos vivendo as consequências geradas por nosso descaso com a alegria e seus reflexos podem ser observados no crescimento gradual da indústria dos videogames em nossa sociedade contemporânea, assim como na gamificação aplicação de elementos e mecânicas de design de jogos em outros contextos, exemplos: marketing, ambientes empresariais, etc. - geral que vem ocorrendo. Questionamos, talvez seja válido repensar os modos pelos quais estamos experienciando não só a educação, mas a vida, pois como já vimos, não separamos o viver do aprender, e se vivemos uma vida desprovida de alegria e potência para a afirmação, o que estamos aprendendo afinal?

O décimo encontro foi um pouco diferente, pois nos propusemos visitar o bairro, conhecer um pouco a realidade vivida pelos adolescentes. Poucos adolescentes participaram deste momento, e entendemos que isto se deu porque o interesse deles, fundamentalmente, é ir para a Universidade jogar. Como nós fomos até o bairro, a atividade, para alguns, perdeu seu objetivo. Ao mesmo tempo, foi um momento em que pudemos conhecer um pouco melhor os adolescentes que se propuseram a conversar conosco, entendendo melhor suas trajetórias de vida e escolhas pessoais.

No encontro seguinte, adequamos nossos encontros para que o jogo aconteça utilizando o Xbox 360 e iPads. No Xbox 360 não há tanta variedade de jogos, continuamos com Kinect Adventures, Dance Central 2 e Kinect Sports e também o jogo para jogar no joystick Alan Wake. No iPad foram instalados vários jogos, de diversos 
tipos, mas os adolescentes estão livres para baixar outros de seu interesse, para dar conta dos desejos que pedem passagem e que guiam o cartógrafo na sua jornada. Os encontros têm seguido com esta sistemática e entendemos que estamos registrando questões positivas à pesquisa, uma vez que os adolescentes demonstram um interesse cada vez maior pelo mundo dos jogos, pois encontraram ali aprendizagens que não se dizem aprendizagens, pois não há o peso da obrigação de aprender, há apenas o desejo por seguir em frente, mas para seguir em frente o aprender é inevitável.

\section{Para além de uma conclusão}

Ao longo de sua existência, a humanidade realizou muitas interações. Cada momento específico da história contou com diferentes ferramentas criadas a partir dessas interações. Os videogames são uma tecnologia atual com a qual nos instrumentalizamos para experienciar novas formas de viver e ser no mundo. Assim como a descoberta do fogo oportunizou novas relações e formas de pensar e estar em sociedade, as tecnologias que surgem hoje advindas de novas interações por nós criadas possuem o mesmo potencial transformador.

Nesse sentido, considerando a utilização da tecnologia como uma ferramenta potencializadora do viver, Lévy (1999) aponta o envolvimento dos sujeitos participantes no uso das tecnologias como um processo possibilitador da produção de aprendizagem. O papel ativo dos sujeitos enquanto autores de sua aprendizagem encontra aporte nos pressupostos do paradigma da complexidade, que se apoia no princípio da não linearidade e da multicausalidade dos fatos, onde existe uma constante (re)criação do aprender/viver, primeiro princípio da teoria da autopoiesis.

Ancorados no primeiro princípio da autopoiesis, nos deparamos com "tudo que é dito, é dito por um observador" (OLIVEIRA, 2010), segundo princípio da autopoieisis, que nos coloca incluídos no fluxo, - fluxo de energia essencial para sistemas complexos transformarem-se, evoluírem e sobreviverem, necessário para combater a entropia - ou seja, nós pesquisadores, assim como sujeitos de pesquisa, somos seres que vivemos no fluxo, e nesse movimento vamos observando, aprendendo e vivendo em constante (re) configuração das nossas ações e atuações que fundam nossa realidade.

Apesar de muitos videogames não exigirem ampla movimentação física, jamais estamos parados. Nossa cognição/subjetivação está em constante devir, em uma dinâmica de (re) configuração - das ações e atuações, frente aos acontecimentos da 
vida. Estar nesse fluxo, permite que estejamos abertos à auto-organizações e autorias necessárias para enfrentar as situações de conflito que os jogos, assim como a vida, nos apresentam. Essa disponibilidade, este estar aberto aos jogos, foi o que observamos como algo importantíssimo para que ocorresse a aprendizagem.

Enfim, ao entendermos a educação por meio de uma perspectiva não linear e complexa - não separando os processos de viver e conhecer, e considerando a inseparabilidade como constitutiva do humano - é que na perspectiva da complexidade acontecem as aprendizagens, em todos os momentos da vida, inclusive e, especialmente para essa pesquisa, quando se joga videogame. Portanto, para que os sujeitos aprendam, é preciso que experienciem, e os videogames, apesar de suas limitações, são fábricas de possibilidades no que se refere a transformações complexificantes e autopoiéticas.

\section{REFERÊNCIAS}

ATLAN, H. Entre o cristal e a fumaça: ensaio sobre a organização do ser vivo. Rio de Janeiro: Jorge Zahar Editora, 1992.

ATLAN, H. Dos Caos à Inteligência Artificial: quando os cientistas se interrogam. São Paulo: Editora UNESP, 1993.

BOETTCHER, D. Ciberespaço: o reencantamento da aprendizagem. Santa Cruz do Sul: EDUNISC, 2003.

CSÍKSZENTMIHÁLYI, M. Beyond boredom and anxiety. London: Jossey-Bass, 1975.

DUPUY, J. P. Nas Origens das Ciências Cognitivas. São Paulo: Editora UNESP, 1996.

ESPINOSA, B. Ética. Belo Horizonte: Autêntica, 2007.

FALABRETTI, E. Rousseau: a educação dos sentimentos e das virtudes. In: OLIVEIRA, P. (Org). Filosofia e Educação: aproximações e convergências. Curitiba: Círculo de Estudos Bandeirantes, 2012, p.178-197.

GEE, J. P. What video games have to teach us about learning and literacy. New York: Palgrave Macmillan, 2004.

GEE, J. P. Why Are Video Games Good For Learning?. Melbourne: Common Ground, 2005.

GOFFMAN, E. Estigma: notas sobre a manipulação da identidade deteriorada. Rio de Janeiro, Zahar, 1982.

GUBES, T. Epistemologia da complexidade. (pseudo-resenha). Disponível em: 
<http://foxguy.blogspot.pt/2009/10/epistemologia-da-complexidade-edgar.html $>$. Acesso em: 10 abr, 2015.

KUHN, T. The structure of Scientific Revolutions. Chicago: University, Chicago Press, 1970.

LÉVY, P. Tecnologias da Inteligência. São Paulo: Ed. 34, 1993.

LÉVY, P. O que é virtual. Trad. Paulo Neves. São Paulo: Ed. 34, 1996.

LÉVY, P. Cibercultura. São Paulo: Ed. 34, 1999.

MATURANA, H. La Educación: um ejercicio de humanidade. Disponível em: <http://bibliorepo.umce.cl/revista_educacion/1995/228/16_19.pdf.>. Acesso em: 22 set. 2011.

MATURANA, H. A ontologia da realidade. Belo Horizonte: Ed. UFMG, 1997.

MATURANA, H.; VARELA, F. De Máquinas e Seres Vivos: autopoiese: a organização do vivo, 3rd ed. Porto Alegre: Artes Médicas, 1997.

MATURANA, H.; VARELA, F., A árvore do conhecimento: as bases biológicas da compreensão humana. São Paulo: Palas Athena, 2001.

MCGONIGAL, J. Reality Is Broken: Why Games Make Us Better and How They Can Change the World. New York: Penguin Books, 2011.

MORIN. E. Complexidade e liberdade. IN: MORIN, E.; PRIGOGINE, I. A Sociedade em busca de valores: para fugir à alternativa entre o cepticismo e o dogmatismo. Lisboa: Instituto Piaget, 1996.

MORIN. E. Contrabandista dos Saberes. PESSIS-PASTERNAK, Guitta. Dos Caos à Inteligência Artificial: quando os cientistas se interrogam. São Paulo: Editora UNESP, 1993.

MORIN. E. Introdução ao Pensamento Complexo. $5^{\text {a }}$ ed. Lisboa: Instituto Piaget, 2008.

MÜLlER, César Augusto; OLIVEIRA, Clara Costa. Emocionar: experiências enquanto acontecimentos utilizando as tecnologias digitais de informação e comunicação. IN: Congresso Ibero-americano em Investigação Qualitativa, $4^{\circ}$, Aracajú, 2015. No prelo.

MURRAY, J. Hamlet no holodeck: o futuro da narrativa no ciberespaço. São Paulo, Itaú Cultura, 2003.

NIETZSCHE, F. W., Além do bem e do mal: prelúdio a uma filosofia do futuro. São Paulo: Companhia das Letras, 1992.

OLIVEIRA, C. C. A Educação como processo auto-organizativo: fundamentos 
teóricos para uma educação permanente e comunitária. Instituto Piaget: Lisboa, 1999.

OLIVEIRA, C. C. Da Cibernética à Autopoiesis: continuidades e descontinuidades. Informática na Educação: teoria \& prática, Porto Algre, v. 12, n. 2, p. 23-34, jul./dez. 2009.

OLSON, D. O Mundo no Papel: as implicações conceituais e cognitivas da leitura e da escrita. São Paulo: Ática, 1997.

ORTEGA Y GASSET, J. Meditação sobre a técnica. Trad. José Francisco Pinto de Almeida Oliveira. Rio de Janeiro: Instituto Liberal, 1991.

PELLANDA, N. M. C. (Org.); BOETTCHER, D. M. (Org.); R.A. (Org.); OLIVEIRA, C. C. (Org.). Aprendizagem e sofrimento: narrativas. Santa Cruz do Sul: EDUNISC, 2012.

PELLANDA, N. M. C. Educação e sofrimento: marcas de um paradigma. In: XIV ENDIPE, 2008, Porto Alegre. Encontro Nacional de Didática e Prática de Ensino. Porto Alegre: Edipucrs, 2008.

PELLANDA, N. M. C. Maturana \& a educação. Belo Horizonte: Autêntica, 2009.

PETRY, A. dos S. Jogo, Autoria e Conhecimento: fundamentos para uma compreensão dos Games. Jundiaí, Paco Editorial, 2014.

ROLNIK, S. Cartografia Sentimental: Transformações Contemporâneas do Desejo. Porto Alegre: Sulina, 2006.

SIMONDON, G. El modo de existência de los objetos técnicos. Buenos Aires: Prometeo, 2007.

VARELA, F. Conhecer as Ciências Cognitivas: tendências e perspectivas. Lisboa: Instituto Piaget, 1994.

\section{Como referenciar este artigo}

LIMBERGER, Leticia Staub.; MÜLLER, César Augusto.; PINTO, Maira Meira. Aprendizagens e videogames. Revista Ibero-Americana de Estudos em Educação, Araraquara/SP, v. 11, n. 3, p.1149-1168, 2016. Disponível em: <https://dx.doi.org/10.21723/riaee.v11.n3.7852>. E-ISSN: 1982-5587.

Submetido em: 08/07/2015

Aprovação Final em: 26/07/2016 